\title{
Clinical utility of ramucirumab in advanced gastric cancer
}

This article was published in the following Dove Press journal:

Biologics:Targets and Therapy

22 September 2015

Number of times this article has been viewed

\section{Matthew MK Chan 1,2 \\ Katrin M Sjoquist ${ }^{1,3}$ \\ John R Zalcberg ${ }^{4}$}

'NHMRC Clinical Trials Centre, University of Sydney, Sydney, NSW, Australia; ${ }^{2}$ Department of Medical Oncology, Central Coast Cancer Centre, Gosford Hospital, Gosford, NSW, Australia; ${ }^{3}$ Cancer Care Centre, St George Hospital, Sydney, NSW, Australia; ${ }^{4}$ School of Public Health and Preventive Medicine, Monash University, Melbourne, VIC, Australia
Correspondence: Matthew MK Chan

Department of Medical Oncology, Central Coast Cancer Centre, Gosford Hospital, Holden Street, Gosford, NSW 2250, Australia

Tel +6I 243209888

Fax +6I 243209800

Email matthew.chan@health.nsw.gov.au
Abstract: Gastric cancer is currently the third most common cause of cancer deaths worldwide. Prognosis remains poor with most patients presenting with advanced or metastatic disease. A better understanding of angiogenesis has led to the investigation of drugs that inhibit the vascular endothelial growth factor (VEGF) pathway including anti-VEGF antibody therapy (eg, bevacizumab), inhibitors of angiogenic receptor tyrosine kinases (eg, sunitinib, sorafenib, apatinib, regorafenib), and inhibitors of vascular endothelial growth factor receptors (VEGFRs) (eg, ramucirumab). Ramucirumab, a VEGFR-2 inhibitor, is the first anti-angiogenic agent approved by the US Food and Drug Administration for use in the treatment of advanced gastric cancers. This review will focus on the clinical utility and potential use of ramucirumab in advanced gastric cancer.

Keywords: ramucirumab, IMC-1121B, gastric cancer, vascular endothelial growth factor receptor-2, angiogenesis, targeted therapy

\section{Introduction}

Gastric cancer is currently the fifth most common cancer and the third most common cause of cancer deaths worldwide, accounting for almost $9 \%$ of all deaths from cancer. ${ }^{1}$ Cure is possible for patients presenting with early stage disease, where surgical resection can be combined with adjuvant chemotherapy with or without radiotherapy. In this setting, improved outcomes have been demonstrated with the addition of perioperative chemotherapy, ${ }^{2}$ post-operative chemotherapy, ${ }^{3-5}$ or post-operative combination chemotherapy with radiotherapy ${ }^{6}$ to radical surgery. However, almost two-thirds of patients will have locally advanced or metastatic disease at presentation which is currently considered incurable, and many of those who initially present with early disease will develop locoregional or distant relapse sometime during the course of their illness. Despite incremental improvements in systemic chemotherapy over many years, the prognosis of patients with advanced gastric cancer remains poor, and until recently, little progress has been made in the development of new chemotherapeutic agents or molecularly targeted therapies that provide a meaningful impact on survival. This review will focus on the clinical utility and potential use of ramucirumab, a monoclonal antibody that blocks vascular endothelial growth factor receptor-2 (VEGFR-2), in advanced gastric cancer.

\section{Advanced gastric cancer Prognosis}

The prognosis of patients with advanced or metastatic gastric cancer is poor with a median survival of approximately 3-4 months with supportive care alone. 
Systemic therapies are the mainstay of treatment with radiotherapy reserved for the management of symptomatic local problems. Traditional cytotoxic chemotherapies remain the backbone of treatment with increasing evidence for incorporation of targeted therapies, including human epidermal growth factor receptor-2 (HER-2) inhibitors and anti-angiogenic agents, in certain settings.

\section{Management}

First-line therapy

In the advanced disease setting, first-line treatment using combination palliative chemotherapy with a platinum (cisplatin or oxaliplatin) and fluoropyrimidine (5-fluorouracil [5-FU] or capecitabine or S-1 [Taiho Pharmaceutical Co., Ltd, Tokyo, Japan]) doublet, or a triplet regimen with the addition of epirubicin or docetaxel, provides a survival benefit and improved quality of life. There is some regional variation in practice with recommended regimens varying between guidelines, although, final selection of a validated doublet or triplet regimen will depend on performance status, co-morbidities, organ function, access to drugs, and local practice. However, outcomes remain poor with a median overall survival (OS) of approximately 9-14 months in patients who receive first-line systemic chemotherapy. ${ }^{7-16}$ In the subset of patients with HER-2 positive advanced gastric cancer, the Phase III Trastuzumab in Gastric Cancer (ToGA) trial has shown that the anti-HER-2 monoclonal antibody, trastuzumab (Herceptin; Hoffman-La Roche Ltd., Basel, Switzerland), has a modest survival benefit in the HER-2 positive population when used in combination with platinum and fluoropyrimidine chemotherapy, when compared with the same chemotherapy alone. ${ }^{17}$

\section{Second-line therapy}

Patients with good Eastern Co-operative Group Performance Status (ECOG PS 0-1) and who develop disease progression following platinum and fluoropyrimidine-based chemotherapy should be offered second-line therapy based on evidence from three randomized, Phase III trials, demonstrating a modest survival benefit for docetaxel or irinotecan monotherapy, as compared with best supportive care. ${ }^{18-20}$ Summaries of these trials are shown in Table 1. A meta-analysis of these trials showed a significant reduction in the risk of death associated with the use of salvage chemotherapy in the second-line setting when compared with supportive care (hazard ratio [HR]: $0.64,95 \%$ CI: $0.52-0.79, P<0.0001) .{ }^{21}$ The optimal second-line regimen is unclear because there have been few trials that have directly compared the efficacy and safety of different second-line treatments. A Japanese trial that compared weekly paclitaxel $\left(80 \mathrm{mg} / \mathrm{m}^{2}\right.$ on Day [D] $1, \mathrm{D} 8$, and D15 and then every [q] 28 days [d]) versus irinotecan $\left(150 \mathrm{mg} / \mathrm{m}^{2}\right.$ on D1 and D15 and then q28d) showed neither superiority for efficacy nor safety for paclitaxel. ${ }^{22}$ For patients who developed disease progression on S-1-based first-line chemotherapy, the TCOG GI-0801/BIRIP trial randomized 130 patients to combination cisplatin $\left(30 \mathrm{mg} / \mathrm{m}^{2}\right.$ on $\mathrm{D} 1$ and then $\mathrm{q} 14 \mathrm{~d})$ plus irinotecan $\left(60 \mathrm{mg} / \mathrm{m}^{2}\right.$ on D1 and then $\left.\mathrm{q} 14 \mathrm{~d}\right)$ or irinotecan alone $\left(150 \mathrm{mg} / \mathrm{m}^{2}\right.$ on D1 and then $\left.\mathrm{q} 14 \mathrm{~d}\right)$. This

Table I Summary of Phase III trials investigating second-line chemotherapy for advanced gastric cancer

\begin{tabular}{|c|c|c|c|c|c|c|c|}
\hline \multirow[t]{2}{*}{ Trial reference } & \multirow[t]{2}{*}{ Country } & \multirow[t]{2}{*}{$\mathbf{n}$} & \multirow[t]{2}{*}{ Regimens } & \multicolumn{4}{|l|}{ Results } \\
\hline & & & & ORR (\%) & DCR (\%) & mPFS (months) & mOS (months) \\
\hline \multicolumn{8}{|c|}{ Post-combination platinum and fluoropyrimidine-based chemotherapy } \\
\hline Thuss-Patience et $\mathrm{al}^{20}$ & Germany & 40 & $\begin{array}{l}\mathrm{BSC} \pm \text { irinotecan }\left(250 \mathrm{mg} / \mathrm{m}^{2}\right. \\
\text { on } \mathrm{DI} \text { and then } \mathrm{q} 2 \mathrm{Id} \text {, increasing } \\
\left.\text { to } 350 \mathrm{mg} / \mathrm{m}^{2} \mathrm{C} 2 \text { if tolerated }\right)\end{array}$ & 0 & 53 & 2.5 & $\begin{array}{l}4.0 \text { vs } 2.4 ; \\
\text { HR: } 0.48, P=0.012\end{array}$ \\
\hline Kang et $\mathrm{al}^{18}$ & Korea & 202 & $\begin{array}{l}\mathrm{BSC} \pm \text { chemotherapy (irinotecan } \\
\mathrm{I} 50 \mathrm{mg} / \mathrm{m}^{2} \text { on } \mathrm{DI} \text { and then qI4d } \\
\text { or docetaxel } 60 \mathrm{mg} / \mathrm{m}^{2} \text { on DI } \\
\text { and then } \mathrm{q} 2 \mathrm{Id} \text { ) }\end{array}$ & NA & NA & NA & $\begin{array}{l}5.3 \text { vs } 3.8 ; \\
\text { HR: } 0.657, P=0.007\end{array}$ \\
\hline Ford et al ${ }^{19}$ & UK & 168 & $\begin{array}{l}\mathrm{BSC} \pm \text { docetaxel }\left(75 \mathrm{mg} / \mathrm{m}^{2}\right. \\
\text { on } \mathrm{DI} \text { and then } \mathrm{q} 2 \mathrm{Id})\end{array}$ & 7 & 53 & 2.8 & $\begin{array}{l}5.2 \text { vs } 3.6 \\
\text { HR: } 0.67, P=0.01\end{array}$ \\
\hline Hironaka et $\mathrm{a}^{22}$ & Japan & 223 & $\begin{array}{l}\text { Weekly paclitaxel }\left(80 \mathrm{mg} / \mathrm{m}^{2} \text { on }\right. \\
\text { DI, D8, and DI5 and then q28d) } \\
\text { vs biweekly irinotecan ( } 150 \mathrm{mg} / \mathrm{m}^{2} \\
\text { on DI and DI5 and then } \mathrm{q} 28 \mathrm{~d})\end{array}$ & $\begin{array}{l}20.9 \text { vs } 13.6 \\
(P=0.24)\end{array}$ & NA & $\begin{array}{l}3.6 \text { vs } 2.3 ; \text { HR: I.I4, } \\
P=0.33\end{array}$ & $\begin{array}{l}9.5 \text { vs } 8.4 ; \\
\text { HR: } 1.13, P=0.38\end{array}$ \\
\hline \multicolumn{8}{|c|}{ Post-S-I-based chemotherapy } \\
\hline Higuchi et a ${ }^{23}$ & Japan & 130 & $\begin{array}{l}\text { Irinotecan }\left(60 \mathrm{mg} / \mathrm{m}^{2}\right)+\text { cisplatin } \\
\left(30 \mathrm{mg} / \mathrm{m}^{2}\right) \mathrm{q} 2 \mathrm{w} \text { vs irinotecan } \\
\left(150 \mathrm{mg} / \mathrm{m}^{2} \mathrm{q} 2 \mathrm{w}\right)\end{array}$ & $\begin{array}{l}22 \text { vs } 16 \\
(P=0.4975)\end{array}$ & $\begin{array}{l}75 \text { vs } 54 \\
(P=0.0162)\end{array}$ & $\begin{array}{l}3.8 \text { vs } 2.8 ; H R: 0.68 \\
P=0.0398\end{array}$ & $\begin{array}{l}\text { I0.7 vs I0.I; } \\
\text { HR: I.00, } P=0.9823\end{array}$ \\
\hline
\end{tabular}

Abbreviations: BSC, best supportive care; C, cycle; d, days; D, day; DCR, disease control rate; HR, hazard ratio; mOS, median overall survival; mPFS, median progression free survival; NA, not available; ORR, overall response rate; q, every. 
showed that cisplatin and irinotecan improved progression free survival (PFS) (3.8 vs 2.8 months; HR: $0.68, P=0.0398$ ) but not OS (10.7 vs 10.1 months; HR: $1.00, P=0.9823) .{ }^{23}$

\section{Molecularly targeted treatments}

A number of molecularly targeted therapies have been tested in advanced gastric cancer including epidermal growth factor receptor (EGFR) inhibitors, cetuximab (Erbitux; Merck Serono, Darmstadt, Germany) ${ }^{24}$ and panitumumab (Vectibix; Amgen Inc., Thousand Oaks, CA, USA), ${ }^{25}$ and the mTOR inhibitor, everolimus (Afinitor; Novartis International AG, Basel, Switzerland) ${ }^{26}$ none of which demonstrated a survival benefit in Phase III trials. A second-line Japanese/Korean study of irinotecan with or without nimotuzumab is ongoing (NCT01813253). An OS advantage was also not demonstrated in the TyTAN study, which is a second-line, Phase III trial of the HER-2 tyrosine kinase inhibitor, lapatinib (Tykerb; GlaxoSmithKline plc, London, UK), in combination with paclitaxel. ${ }^{27}$ Phase III trials investigating trastuzumab emtansine (Kadcyla TDM-1; Hoffman-La Roche Ltd) in the GATSBY trial and pertuzumab (Perjeta; Hoffman-La Roche Ltd) in the JACOB trial are ongoing. ${ }^{28}$ Trials investigating mesenchymal epithelial transition factor (MET) pathway inhibitors, rilotumumab (AMG102; Amgen), have been halted due to an excess number of deaths related to the study drug and a randomized Phase II trial of mFOLFOX6 (oxaliplatin $85 \mathrm{mg} / \mathrm{m}^{2} \mathrm{D} 1$, leucovorin $400 \mathrm{mg} / \mathrm{m}^{2} \mathrm{D} 1,5$-FU bolus $400 \mathrm{mg} / \mathrm{m}^{2} \mathrm{D} 1$, and 5-FU infusion $2,400 \mathrm{mg} / \mathrm{m}^{2}$ over 48 hours, and then q14d) with or without onartuzumab (MetMab; Hoffman-La Roche Ltd) did not improve PFS. ${ }^{29}$ A Phase III study investigating a poly ADP ribose polymerase inhibitor olaparib in combination with paclitaxel chemotherapy is ongoing (NCT01924533) following Phase II data in the second-line which showed an OS benefit in the olaparib group. ${ }^{30}$

Two studies that examined the role of bevacizumab (Avastin; Hoffman-La Roche Ltd) directed against the vascular endothelial growth factor (VEGF) did not demonstrate a survival benefit when used in combination with first-line chemotherapy. ${ }^{31,32}$ However, there is evidence from two Phase III studies of the VEGFR-2 inhibitor, ramucirumab, ${ }^{33,34}$ and one Phase III study of the VEGFR-2 tyrosine kinase inhibitor, apatinib, ${ }^{35}$ to suggest that VEGFR-2 is an important, clinically relevant target in advanced gastric cancer.

\section{Anti-angiogenesis therapy Tumor angiogenesis and the VEGF pathway}

Inducing angiogenesis to support the tumor-associated neovasculature is considered a key hallmark of cancer. ${ }^{36}$
The VEGFs that mediate these proangiogenic effects are homodimeric glycoproteins that include VEGF-A, VEGF-B, VEGF-C, VEGF-D, and placental growth factor. ${ }^{37,38}$ The angiogenic process is complex and involves the interaction between VEGF and its receptors including VEGF-1, VEGF-2, and VEGF-3. VEGFR-2 is a type II cell surface transmembrane kinase receptor that is mainly expressed on vascular endothelial cells. ${ }^{39}$ Binding of VEGF to VEGFR-2 results in phosphorylation and activation of multiple downstream pathways, activating a signaling cascade which promotes tumor angiogenesis. ${ }^{40}$ Despite a tenfold lower binding affinity of VEGF-A to VEGFR-2 compared to VEGFR-1, VEGFR-2 is considered to be the main driver of angiogenesis because the phosphorylated downstream targets are more potent signaling intermediaries. ${ }^{39,41}$ Therefore, it has been a key target for drug development. The VEGF pathway has also been closely investigated to help identify potential therapeutic strategies that may inhibit angiogenesis and tumor growth in order to develop new treatments. Strategies developed to inhibit the VEGF pathway are shown in Figure 1 and include anti-VEGF antibody therapy (eg, bevacizumab), inhibitors of angiogenic receptor tyrosine kinases (eg, sunitinib, pazopanib, sorafenib, regorafenib), inhibitors of VEGFR-2 tyrosine kinases (eg, apatinib), and anti-VEGFR antibody therapy (eg, ramucirumab). Currently approved anti-angiogenic agents for various tumor types including lung, renal, and colon cancers include bevacizumab, sunitinib, pazopanib, and sorafenib. Increased expression of VEGF in tumor and serum has been shown in gastric cancer which is associated with poor prognosis and more aggressive disease. ${ }^{42,43}$ This suggests that angiogenesis may be an important target for gastric cancer and that inhibitors of the VEGF pathway may be a useful anti-tumor strategy.

\section{Anti-VEGF antibody (bevacizumab)}

The Avastin in Gastric Cancer (AVAGAST) study ${ }^{31}$ was a large $(n=774)$, multicenter, international, Phase III trial of capecitabine and cisplatin chemotherapy with $(n=387)$ or without ( $\mathrm{n}=387$ ) bevacizumab (Avastin; Hoffman-La Roche Ltd). This study showed a better response rate (46\% vs 37\%; $P=0.0315$ ) and longer PFS (6.7 vs 5.3 months; HR: 0.8, 95\% CI: $0.68-0.93, P=0.0037)$ in the bevacizumab group. However, this study did not meet its primary endpoint of improved OS (12.1 vs 10.1 months; HR: 0.87, 95\% CI: $0.73-1.03, P=0.1002)$. Interestingly, on subgroup analysis there were differences in efficacy across the geographic regions involved in the trial (Asia, Europe, and Pan-America) with superior efficacy in Pan-America compared to Asia. However, it is unclear whether these differences are due to 


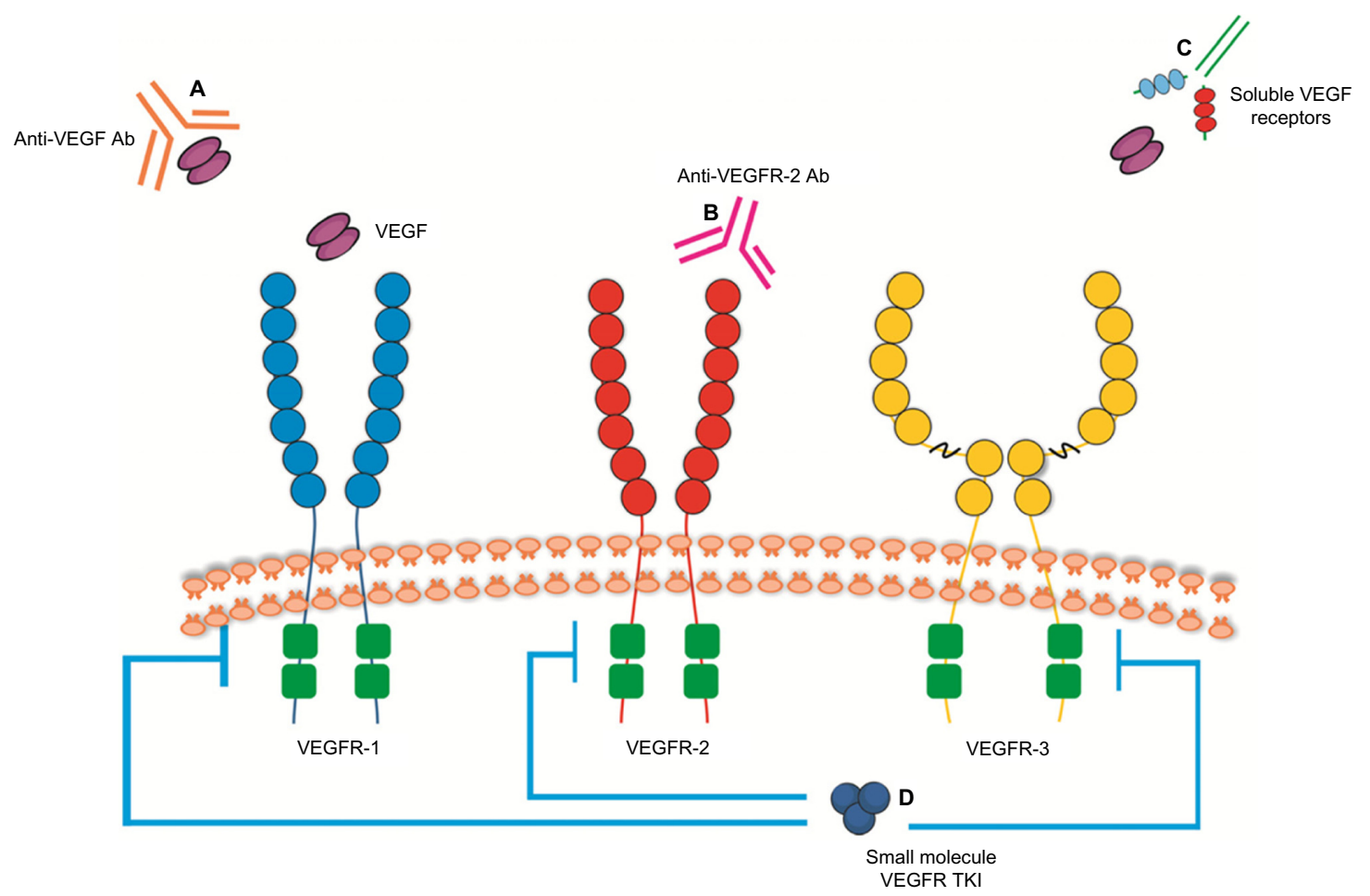

Figure I Strategies to inhibit VEGF pathway signaling.

Notes: (A) anti-VEGF antibody (eg, bevacizumab); (B) anti-VEGFR-2 antibody (eg, ramucirumab); (C) soluble VEGF receptors (eg, aflibercept); and (D) VEGF receptor tyrosine kinase inhibitors (eg, sunitinib, sorafenib, regorafenib, apatinib [anti-VEGFR-2 TKI]).

Abbreviations: Ab, antibody; TKI, tyrosine kinase inhibitor; VEGF, vascular endothelial growth factor; VEGFR, vascular endothelial growth factor receptor.

pharmacogenetics or variations in clinical practice such as the use of subsequent lines of chemotherapy after initial progression on first-line therapy. This trial was followed by the AVATAR study, which was a randomized, Phase III trial of similar design, in Chinese patients, which did not show any improvement in OS (10.5 vs 11.4 months; HR: 1.11, $P=0.56)$ nor PFS (6.3 vs 6.0 months; HR: 0.89, $P=0.47){ }^{32}$ Based on the results of these studies, there is currently no role for anti-VEGF monoclonal antibodies such as bevacizumab in advanced gastric cancer outside of clinical trials.

\section{Angiogenic receptor tyrosine kinases (sunitinib, sorafenib)}

Sunitinib (Sutent; Pfizer Inc., New York, NY, USA ) and sorafenib (Nexavar; Bayer AG, Leverkusen, Germany) are small molecule, multi-targeted, tyrosine kinase inhibitors that inhibit VEGF-1, 2, and 3. A second-line Phase II trial, for advanced gastric cancer, randomized patients to docetaxel (60 $\mathrm{mg} / \mathrm{m}^{2} \mathrm{D} 1$ and then q21d), with or without sunitinib (37.5 $\mathrm{mg}$ oral daily). This showed a higher objective response rate but the differences in median time to progression (3.9 vs 2.6 months, $P=0.206)$ and median OS (8.0 vs 6.6 months, $P=0.802)$ were not statistically significant. ${ }^{44}$ Sorafenib (400 mg oral twice daily) has been studied in combination with docetaxel $\left(75 \mathrm{mg} / \mathrm{m}^{2} \mathrm{D} 1\right.$ and then $\left.\mathrm{q} 21 \mathrm{~d}\right)$ and cisplatin
( $75 \mathrm{mg} / \mathrm{m}^{2} \mathrm{D} 1$ and then $\mathrm{q} 21 \mathrm{~d}$ ) in a first-line, Phase II study, in advanced gastric cancer. This study showed a median survival of 13.6 months, objective tumor response was seen in $41 \%$, with the main grade $3 / 4$ adverse event being neutropenia. ${ }^{45}$ Regorafenib (160 mg po D1-21 and then q28d) has shown sufficient activity and safety in a randomized, placebo controlled, Phase II trial (INTEGRATE), with a longer PFS (11.1 vs 3.9 weeks; HR: $0.41, P<0.0001$ ) demonstrated to warrant consideration for Phase III evaluation. ${ }^{46}$

\section{Anti-VEGFR-2 receptor tyrosine kinases (apatinib)}

Apatinib is a small molecule tyrosine kinase inhibitor that targets VEGFR-2. Phase II studies of advanced gastric cancer in chemotherapy refractory patients showed promising activity with improvements in PFS and $\mathrm{OS}^{47}$ which have been confirmed in a recently completed Phase III study, presented in abstract form, demonstrating an improvement in median OS (195 vs 140 d; HR: $0.71,95 \%$ CI: $0.54-0.94, P<0.016) .{ }^{35}$ The full manuscript is keenly awaited.

\section{Anti-VEGFR-2 antibody (ramucirumab)}

Ramucirumab (Cyramza ${ }^{\mathrm{TM}}$; Eli Lilly and Company, Indianapolis, IN, USA, IMC-1121B, LY30009806) is a novel, 
fully humanized, IgG1 monoclonal antibody that binds to the extracellular domain of VEGFR-2. ${ }^{41}$ This specifically and potently blocks with high affinity the binding of VEGFR-2 to its ligands including VEGF-A, VEGF-C, and VEGF-D thus inhibiting receptor activation of downstream VEGF signaling pathways resulting in reduced tumor neovascularization and growth. ${ }^{41}$ Ramucirumab is the first monoclonal antibody that targets angiogenesis to show a survival benefit in advanced gastric cancer. It has also been shown to improve OS and PFS in Phase III trials of non-small-cell lung cancer (NSCLC) and colorectal cancer but not of breast cancer or hepatocellular carcinoma (HCC) (Table 2). ${ }^{48-51}$

\section{Pharmacology}

Ramucirumab is administered intravenously with dosing based on body weight. It is mixed with normal saline for administration. At the standard recommended dose of $8 \mathrm{mg} /$ $\mathrm{kg}$ administered by intravenous infusion over 60 minutes q2 weeks, the pharmacokinetic profile of ramucirumab at steady state is characterized by a half-life of 200-300 hours. ${ }^{52}$

\section{Preclinical studies}

The development of anti-VEGFR-2 antibodies specific for murine (fetal liver kinase 1, Flk-1) and human (kinaseinsert domain receptor, KDR) forms of the VEGFR-2 was required due to species-specific differences. DC101, a mouse-specific anti-Flk-1 monoclonal antibody, was shown to potently block VEGF receptor binding to its ligands in vitro interfering with VEGF pathway signaling. ${ }^{53}$ DC-101 was then shown in mouse xenograft models to inhibit tumor growth in vivo supporting the therapeutic strategy of using an anti-VEGFR-2 antibody to suppress tumor-induced neovascularization in angiogenesis-dependent tumors. ${ }^{54} \mathrm{~A}$ phage display library and standard hybridoma technology were used to develop a high-affinity anti-KDR antibody which was shown to block the VEGF-KDR interaction thus inhibiting receptor activation and associated downstream signaling pathways. ${ }^{55,56} \mathrm{~A}$ minimum trough level of $20 \mu \mathrm{g} /$ $\mathrm{mL}$ was determined in xenograft models to have sufficient anti-tumor activity for use as a target for subsequent clinical trials. ${ }^{57}$
Phase I/II studies

An initial Phase I safety and dose-finding study was conducted in 37 patients with advanced solid malignancies including patients with gastric cancer who were refractory to treatment and did not have any standard treatment options (Table 3). ${ }^{52}$ Using a standard $3+3$ dose escalation trial design, after evaluating seven dose levels between $2 \mathrm{mg} / \mathrm{kg}$ and $16 \mathrm{mg} / \mathrm{kg}$, this study found a maximum tolerated dose of $13 \mathrm{mg} / \mathrm{kg}$ weekly although pharmacokinetic studies demonstrated that clearance was saturated at $8 \mathrm{mg} / \mathrm{kg}$. The predefined $\mathrm{C}_{\min }(20 \mu \mathrm{g} / \mathrm{mL})$ based on preclinical xenograft data was met in all patients. This study showed a safety profile that was similar to bevacizumab with grade 3 adverse events that included hypertension, deep venous thrombosis, vomiting, and proteinuria. Of the 27 patients who had measurable disease, four patients had partial responses lasting at least 12 weeks including one patient with gastric cancer and 23 patients who had stable disease as their best response. No patient had a complete response. Another Phase I study of 14 patients that examined 2-weekly dosing at $6-10 \mathrm{mg} / \mathrm{kg}$ showed that the target trough level of $20 \mu \mathrm{g} / \mathrm{mL}$ was met. ${ }^{58}$ Based on these studies, ramucirumab was evaluated at the $8 \mathrm{mg} / \mathrm{kg}$ dose q2 weeks in ongoing studies.

Phase II studies of ramucirumab in combination with paclitaxel and docetaxel in patients with gastric cancer have been published in abstract form. ${ }^{59,60}$ These studies showed that co-administration of ramucirumab with paclitaxel or docetaxel chemotherapy does not affect the pharmacokinetics of the chemotherapy agents and the side effects reported were consistent with the safety profiles of the individual drugs.

A Phase II study of mFOLFOX6 (oxaliplatin $85 \mathrm{mg} / \mathrm{m}^{2}$ D1, leucovorin $400 \mathrm{mg} / \mathrm{m}^{2} \mathrm{D} 1,5-\mathrm{FU}$ bolus $400 \mathrm{mg} / \mathrm{m}^{2} \mathrm{D} 1$, and 5 -FU infusion $2,400 \mathrm{mg} / \mathrm{m}^{2}$ over 48 hours, and then q14d) plus ramucirumab ( $8 \mathrm{mg} / \mathrm{kg}$ q14d) versus mFOLFOX6 plus placebo in first-line treatment of advanced gastric and esophageal cancer accrued 168 patients and showed a median PFS of 6.4 versus 6.7 months (HR: $0.98, P=0.89$ ) and median OS of 11.7 versus 11.5 months (HR: 1.08$).{ }^{61}$ Disease control rate was better in the ramucirumab group (85\% vs 67\%). Subgroup analysis by tumor site showed that for patients with gastric cancer, the median PFS was 8.7 versus 7.1 months

Table 2 Summary of Phase III trials of ramucirumab in other tumor types

\begin{tabular}{llllll}
\hline Trial ID & Tumor & Line & $\mathbf{n}$ & Regimens & Status \\
\hline NCTOI I $68973^{48}$ & NSCLC & Second & I,253 & Ramucirumab + docetaxel vs placebo + docetaxel & Improved OS and PFS \\
NCTOII $83780^{50}$ & Colon & Second & I,050 & Ramucirumab + FOLFIRI vs placebo + FOLFIRI & Improved OS \\
NCTOII $40347^{51}$ & HCC & Second & 565 & Ramucirumab + BSC vs placebo + BSC & Did not meet primary end point OS \\
NCT0070332649 & Breast & First & I,I44 & Ramucirumab + docetaxel vs placebo + docetaxel & Did not meet primary end point PFS \\
\hline
\end{tabular}

Abbreviations: BSC, best supportive care; FOLFIRI, fluorouracil and irinotecan; HCC, hepatocellular carcinoma; NSCLC, non-small-cell lung cancer; OS, overall survival; PFS, progression free survival. 
Table 3 Summary of trials investigating ramucirumab for advanced gastric cancer

\begin{tabular}{|c|c|c|c|c|c|c|c|c|c|}
\hline \multirow[t]{2}{*}{ Trial ID } & \multirow[t]{2}{*}{ Phase } & \multirow[t]{2}{*}{ Line } & \multirow[t]{2}{*}{ Indication } & \multirow[t]{2}{*}{$\mathbf{n}$} & \multirow[t]{2}{*}{ Regimens } & \multicolumn{4}{|l|}{ Results } \\
\hline & & & & & & ORR (\%) & DCR (\%) & mPFS (months) & mOS (months) \\
\hline NCT00793975 52 & 1 & Last & Solid tumors & 37 & Ramucirumab & NA & 73 & NA & NA \\
\hline NCT00786383 & 1 & Last & Solid tumors & 25 & Ramucirumab & NA & NA & NA & NA \\
\hline NCTOI005355 & I & Last & Solid tumors & 17 & Ramucirumab & NA & NA & NA & NA \\
\hline NCTOI 253525 & 1 & Last & Gastric & 6 & Ramucirumab + paclitaxel & NA & NA & NA & NA \\
\hline NCT0I5I5306 & I & Last & Solid tumors & 40 & Ramucirumab + paclitaxel & NA & NA & NA & NA \\
\hline NCT0I567I63 & 1 & Last & Solid tumors & 22 & Ramucirumab + docetaxel & NA & NA & NA & NA \\
\hline NCT0I 634555 & 1 & Last & Solid tumors & 29 & Ramucirumab + FOLFIRI & NA & NA & NA & NA \\
\hline NCT0I $246960^{61}$ & ॥ & First & $\begin{array}{l}\text { Esophageal + } \\
\text { gastric }\end{array}$ & 168 & Ramucirumab + FOLFOX & 45 vs 46 & 85 vs 67 & $\begin{array}{l}6.4 \text { vs } 6.7 \\
\text { HR: } 0.98, P=0.89\end{array}$ & $\begin{array}{l}\text { II.7 vs II.5; } \\
\text { HR: I.08 }\end{array}$ \\
\hline $\begin{array}{l}\text { NCT009I } 7384 \\
\text { (REGARD) }^{33}\end{array}$ & III & Second & Gastric & 355 & $\begin{array}{l}\text { Ramucirumab }+ \text { BSC } \\
(n=238) \text { vs placebo }+ \text { BSC } \\
(n=117)\end{array}$ & 3 vs 3 & 49 vs 23 & $\begin{array}{l}2 . I \text { vs I.3; } \\
\text { HR: } 0.48 \\
P<0.000 \text { I }\end{array}$ & $\begin{array}{l}5.2 \text { vs } 3.8 \\
\text { HR: } 0.78 \\
P=0.047\end{array}$ \\
\hline $\begin{array}{l}\text { NCTOI I } 70663 \\
(\text { RAINBOW) }\end{array}$ & III & Second & Gastric & 665 & $\begin{array}{l}\text { Ramucirumab }+ \text { paclitaxel } \\
(n=330) \text { vs placebo }+ \\
\text { paclitaxel }(n=335)\end{array}$ & 28 vs 16 & 80 vs 64 & $\begin{array}{l}4.4 \text { vs } 2.9 \\
\text { HR: } 0.634 \\
P<0.000 \text { I }\end{array}$ & $\begin{array}{l}9.6 \text { vs } 7.4 \\
\text { HR: } 0.807 \\
P=0.0169\end{array}$ \\
\hline
\end{tabular}

Abbreviations: BSC, best supportive care; FOLFIRI, fluorouracil and irinotecan; FOLFOX, fluorouracil and oxaliplatin; ORR, overall response rate; DCR, disease control rate; mPFS, median progression free survival; HR, hazard ratio; mOS, median overall survival; NA, not available.

(HR: $0.77, P=0.28$ ) and OS 14.6 versus 12.5 months. These data suggest that mFOLFOX6 may be worth examining in a Phase III trial as first-line treatment for patients with advanced gastric cancer only.

\section{Efficacy studies, including any combinational studies}

\section{Phase III studies}

There have been six Phase III trials of ramucirumab completed to date including studies in breast cancer, hepatocellular cancer, colorectal cancer, NSCLC, as well as two in advanced gastric cancer (Table 2).

The landmark REGARD trial (NCT00917384) of ramucirumab was the first study of an anti-angiogenic targeted drug to demonstrate a survival benefit in patients with advanced gastric cancer. ${ }^{33}$ This was a large, multicenter, randomized, Phase III trial designed to evaluate the efficacy of second-line ramucirumab monotherapy for advanced gastric cancer (Table 3). Patients who were ECOG PS 0-1 were required to have disease progression within 4 months of first-line metastatic treatment or 6 months of adjuvant treatment with platinum or fluoropyrimidine-based chemotherapy. Three hundred and fifty-five patients received best supportive care and were randomized $2: 1$ to receive either ramucirumab $(8 \mathrm{mg} / \mathrm{kg}$ intravenous infusion q2 weeks) or placebo until disease progression or unacceptable toxicity. No treatment cross-over was permitted. Intention to treat analysis was used. The median treatment duration was 8 weeks in the ramucirumab group and 6 weeks in the placebo group. There was an improvement in PFS in the ramucirumab treated group (HR: 0.483, 95\% CI: $0.376-0.620, P<0.0001)$ with median PFS of 2.1 months for ramucirumab and 1.3 months for placebo. There was an improvement in OS in the ramucirumab treated group (HR: 0.776, 95\% CI: $0.603-0.998, P=0.047)$ with a median OS of 5.2 months for the ramucirumab and 3.8 months for the placebo treated groups, respectively. The objective response rate based on investigator-determined RECIST (Response Evaluation Criteria in Solid Tumors) criteria was 3\% in both groups. However, the disease control rate was higher for ramucirumab $(49 \%)$ than placebo $(23 \%)$. The authors concluded that VEGFR-2 is an important target in gastric cancer given the benefits in OS seen in patients with advanced gastric cancer who have progressed after first-line treatment with platinum or fluoropyrimidine-based chemotherapy.

The RAINBOW trial (NCT01170663) was a large, international, multicenter, randomized, double-blind, placebo-controlled, Phase III trial designed to evaluate the use of paclitaxel with or without ramucirumab in patients with previously treated advanced gastric cancer. ${ }^{34}$ Patients were required to have disease progression within 4 months of completing first-line chemotherapy (platinum plus fluoropyrimidine with or without an anthracycline). Six hundred and sixty-five patients received paclitaxel $\left(80 \mathrm{mg} / \mathrm{m}^{2}\right.$ on D1, D8, D15, and then q28d) and were randomized to receive either ramucirumab, $8 \mathrm{mg} / \mathrm{kg}$ D1 and then q2 weeks $(n=330)$, or placebo $(n=335)$ until disease progression, unacceptable toxicity, or withdrawal of consent. No treatment cross-over was permitted. Intention to treat analysis 
was used. The median treatment duration was 18.0 weeks in the paclitaxel plus ramucirumab group and 12.0 weeks in the paclitaxel plus placebo group. The median PFS was 4.4 months for the paclitaxel plus ramucirumab and 2.9 months for the paclitaxel plus placebo groups (HR: 0.635, 95\% CI: $0.536-0.752, P<0.0001)$. The median OS was 9.6 months for paclitaxel plus ramucirumab and 7.4 months for paclitaxel plus placebo arms of the study (HR: 0.807, 95\% CI: $0.678-0.962, P=0.017)$. The objective response rate $(28 \%$ vs $16 \%, P=0.0001)$ and the disease control rate ( $80 \%$ vs $64 \%, P<0.001$ ), based on investigator-determined RECIST assessments, were both better in the paclitaxel plus ramucirumab group.

The RAINBOW trial is the largest trial of second-line therapy in gastric cancer to date. Although the median OS of patients treated with paclitaxel plus ramucirumab in the RAINBOW trial was higher than the median OS of patients treated with ramucirumab monotherapy in the REGARD trial, the REGARD trial included more heavily pretreated patients and did not include any concurrent chemotherapy. As these trials are not directly comparable, the additional benefit of adding chemotherapy to ramucirumab as secondline therapy is not known and the optimal treatment strategy remains uncertain. However, these studies compare favorably with second-line studies of chemotherapy alone. Ongoing trials investigating ramucirumab in advanced gastric cancer, outlined in Table 4, include an international, multicenter, Phase III trial of cisplatin plus capecitabine with, or without, ramucirumab as first-line treatment for gastric cancer (NCT02314117).

A summary of Phase III trials of ramucirumab in other tumor types are summarized in Table 2. A survival benefit was demonstrated for NSCLC and colon cancer but not for HCC or breast cancer. ${ }^{48-51}$ Interestingly, the subset of patients with elevated baseline alpha-fetoprotein who received treatment with ramucirumab for advanced HCC did show a survival benefit making this a promising potential predictive biomarker for these patients. It is not clear if the absence of a survival benefit seen in HER-2 negative metastatic breast cancer, when ramucirumab was added to first-line docetaxel chemotherapy, is due to the choice of chemotherapy partner or a more general lack of efficacy of anti-angiogenic strategies for this tumor type.

\section{Safety and tolerability Toxicity}

Overall, ramucirumab is well tolerated (Tables 5 and 6). In the REGARD trial of ramucirumab versus placebo, the most frequent grade 3 or above adverse events were hypertension ( $8 \%$ vs $3 \%$ ), abdominal pain ( $6 \%$ vs $3 \%$ ), and arterial thromboembolism ( $1 \%$ vs $0 \%$ ). There was no increased risk of grade 3 fatigue ( $6 \%$ vs $10 \%$ ), decreased appetite ( $3 \%$ vs $3 \%$ ), vomiting ( $3 \%$ vs $4 \%$ ), anemia ( $6 \%$ vs $8 \%$ ), bleeding ( $3 \%$ vs $3 \%$ ), venous thrombosis ( $1 \%$ vs $4 \%$ ), proteinuria ( $<1 \%$ vs $0 \%$ ), gastrointestinal perforation $(<1 \%$ vs $<1 \%$ ), fistula formation $(<1 \%$ vs $<1 \%$ ), or infusion-related reactions ( $0 \%$ vs $0 \%$ ) associated with ramucirumab use. More patients had to discontinue the drug due to an adverse event in the ramucirumab group compared to placebo (10\% vs $6 \%$ ). In the RAINBOW trial of paclitaxel plus ramucirumab versus paclitaxel, the most frequent grade 3 or above adverse events were neutropenia ( $41 \%$ vs $19 \%)$, leucopenia $(17 \%$ vs $7 \%$ ), hypertension ( $14 \%$ vs $2 \%$ ), abdominal pain ( $6 \%$ vs $4 \%$ ), and fatigue ( $12 \%$ vs $5 \%$ ). The rate of febrile neutropenia was similar between the two treatment groups (3\% vs $2 \%$ ). There was no increased rate of treatment discontinuation or treatment-related death in the paclitaxel plus ramucirumab group. Further safety and efficacy data based on the real world use of ramucirumab would be informative as this treatment has only a modest survival benefit. In particular, safety issues such as the use of ramucirumab in patients with the primary tumor in-situ ought to be examined given the risks

Table 4 Ongoing clinical trials investigating ramucirumab for advanced gastric cancer

\begin{tabular}{|c|c|c|c|c|c|c|}
\hline Trial ID & Phase & Line & Intervention and schedule & Recruitment & Projected accrual & Country \\
\hline NCT0I682I35 & I & Last line & Ramucirumab & Closed to recruitment & 26 & Chinese study \\
\hline NCT020822I0 & $\mathrm{lb} / \mathrm{II}$ & Advanced cancers & Ramucirumab + LY2875358 & Recruiting & 70 & US study \\
\hline NCT0I983878 & II & Second line & Ramucirumab & Closed to recruitment & 33 & Japanese study \\
\hline NCT02359058 & I & First line & $\begin{array}{l}\text { Ramucirumab + other anti- } \\
\text { cancer drugs }^{\mathrm{a}}\end{array}$ & Not yet open & 18 & Japanese study \\
\hline NCT023।799। & II & Second line & Ramucirumab + nab-paclitaxel & Not yet open & 65 & US study \\
\hline NCT023 I4II7 & III & First line & $\begin{array}{l}\text { Cisplatin + capecitabine } \pm \\
\text { ramucirumab }\end{array}$ & Recruiting & 616 & $\begin{array}{l}\text { International } \\
\text { study }\end{array}$ \\
\hline
\end{tabular}

Notes: aGroup I: capecitabine + cisplatin, group 2: S-I + cisplatin, group 3: S-I + oxaliplatin. 
Table 5 Adverse events, according to grade

\begin{tabular}{|c|c|c|c|c|}
\hline & \multicolumn{2}{|c|}{ Ramucirumab ( $n=236)$} & \multicolumn{2}{|c|}{ Placebo $(n=|| 15)$} \\
\hline & Any event & Grade $\geq 3$ & Any event & Grade $\geq 3$ \\
\hline Fatigue* & $84(36 \%)$ & $15(6 \%)$ & $46(40 \%)$ & II (10\%) \\
\hline Abdominal pain ${ }^{\dagger}$ & $68(29 \%)$ & $14(6 \%)$ & $32(28 \%)$ & $3(3 \%)$ \\
\hline Decreased appetite & $57(24 \%)$ & $8(3 \%)$ & $26(23 \%)$ & $4(3 \%)$ \\
\hline Vomiting & $47(20 \%)$ & $6(3 \%)$ & $29(25 \%)$ & $5(4 \%)$ \\
\hline Constipation & $36(15 \%)$ & $\mathrm{I}(<\mathrm{I} \%)$ & $26(23 \%)$ & $3(3 \%)$ \\
\hline Anaemia $^{\ddagger}$ & $35(15 \%)$ & $15(6 \%)$ & $17(15 \%)$ & $9(8 \%)$ \\
\hline Dysphagia & $25(11 \%)$ & $5(2 \%)$ & $12(10 \%)$ & $5(4 \%)$ \\
\hline Dyspnoea & $22(9 \%)$ & $4(2 \%)$ & $15(13 \%)$ & $7(6 \%)$ \\
\hline \multicolumn{5}{|l|}{ Adverse events of special interest } \\
\hline Hypertension & $38(16 \%)$ & $18(8 \%)$ & $9(8 \%)$ & $3(3 \%)$ \\
\hline Bleeding or haemorrhage ${ }^{\pi}$ & $30(13 \%)$ & $8(3 \%)$ & $13(11 \%)$ & $3(3 \%)$ \\
\hline Arterial thromboembolism" & $4(2 \%)$ & $3(1 \%)$ & 0 & 0 \\
\hline Venous thromboembolism** & $9(4 \%)$ & $3(1 \%)$ & $8(7 \%)$ & $5(4 \%)$ \\
\hline Proteinuria & $7(3 \%)$ & $\mathrm{I}(<\mathrm{l} \%)$ & $3(3 \%)$ & 0 \\
\hline Gastrointestinal perforation & $2(<1 \%)$ & $2(<1 \%)$ & $\mathrm{I}(<\mathrm{l} \%)$ & $\mathrm{I}(<\mathrm{I} \%)$ \\
\hline Fistula formation & $\mathrm{I}(<1 \%)$ & $\mathrm{I}(<\mathrm{I} \%)$ & $\mathrm{I}(<1 \%)$ & $\mathrm{I}(<\mathrm{I} \%)$ \\
\hline Infusion-related reaction & $\mathrm{I}(<\mathrm{I} \%)$ & 0 & $2(2 \%)$ & 0 \\
\hline Cardiac failure & $\mathrm{I}(<\mathrm{I} \%)$ & 0 & 0 & 0 \\
\hline
\end{tabular}

Notes: Data are $\mathrm{n}(\%)$, unless otherwise indicated. *Includes asthenia. tincludes upper or lower abdominal pain and hepatic pain. $\ddagger$ Includes decreased haematocrit and red blood-cell count. Includes increased blood pressure. "Includes epistaxis, gastric haemorrhage, gastrointestinal haemorrhage, gingival bleeding, haematemesis, haematoma, haemorrhage, and upper gastrointestinal haemorrhage. "Includes angina pectoris, cardiac arrest, cerebral ischaemia, cerebrovascular accident, myocardial infarction, and myocardial ischaemia. **Includes pulmonary embolism, deep vein thrombosis, thrombosis and venous thrombosis in a limb. Reprinted from The Lancet, volume 283 , Fuchs CS, Tomasek J, Yong CJ, et al, Ramucirumab monotherapy for previously treated advanced gastric cancer or gastro-oesophageal junction adenocarcinoma (REGARD): an international, randomised, multi-centre, placebo-controlled, phase 3 trial, pages 31-39, Copyright @ 2014, with permission from Elsevier. ${ }^{33}$

of bowel perforation with some of the other anti-angiogenic drugs like bevacizumab.

\section{Patient reported outcomes}

Quality of life was examined as a secondary outcome in the REGARD study. ${ }^{33}$ The European Organization for Research and Treatment of Cancer (EORTC) Quality of life Questionnaire C30 (QLQ-C30 version 3.0) was completed by patients at baseline, 6, 12, and 18 weeks of treatment. Although 97\% of patients in the best supportive care (BSC) plus ramucirumab group and $94 \%$ of patients in the BSC plus placebo group had baseline quality of life data, only $48 \%$ of patients receiving ramucirumab and $25 \%$ of patients receiving placebo had quality of life data obtained at week 6 because of treatment discontinuation mostly due to disease progression. Although there was a greater proportion of patients who reported stable or improved global quality of life in the ramucirumab group, this was not statistically significant when compared with the placebo treated group $(P=0.23)$. Patients in the ramucirumab group maintained ECOG PS longer than the placebo group (5.1 vs 2.4 months, HR: $0.59, P=0.002$ ). Given the poor prognosis of patients with advanced gastric cancer, patient reported outcomes may need to be collected more frequently.

There were only preliminary quality of life results reported within the primary manuscript of the RAINBOW study which was a secondary outcome measure of the study. ${ }^{34}$ The EORTC QLQ-C30 version 3.0 and the EuroQoL fivedimensional, three-level health status questionnaire (EQ5D-3L) were completed by patients at baseline, q42d while on study and at study discontinuation. Ninety-eight percent of patients in both groups had baseline quality of life data and $64 \%$ of patients receiving ramucirumab plus paclitaxel and $61 \%$ of patients receiving placebo plus paclitaxel had end of treatment quality of life data. The baseline and end of treatment quality of life scores from the EORTC QLQ-C30 were similar in both treatment groups and we await further details to be published in a subsequent manuscript.

\section{Potential place in therapy}

There has been no universally accepted approach for secondline treatment of advanced gastric cancer. However, recent Phase III studies and meta-analyses of chemotherapy as well as Phase III studies of ramucirumab would suggest that appropriate patients with good performance status should be considered and that they do benefit from treatment with active systemic therapy, after progression on standard first-line chemotherapy. ${ }^{18-21,33,34}$ Based on the results of the REGARD study, the US Food and Drug Administration approved ramucirumab, in April 2014, as monotherapy, in patients with advanced or metastatic gastric or gastroesophageal junction adenocarcinoma who have progressed following treatment 
Table 6 Treatment related side effects occurring in at least 10\% of patients on ramucirumab plus paclitaxel, irrespective of causality

\begin{tabular}{|c|c|c|c|c|c|c|c|c|}
\hline & \multicolumn{4}{|c|}{ Ramucirumab plus paclitaxel $(n=327)$} & \multicolumn{4}{|c|}{ Placebo plus paclitaxel $(n=329)$} \\
\hline & Grades I-2 & Grade 3 & Grade 4 & $\overline{\text { Grade } 5}$ & Grades I-2 & Grade 3 & Grade 4 & Grade 5 \\
\hline $\begin{array}{l}\text { Any patients with a treatment- } \\
\text { emergent adverse event }\end{array}$ & $57(17 \%)$ & $155(47 \%)$ & $73(22 \%)$ & $39(12 \%)$ & $116(35 \%)$ & 128 (39\%) & $27(8 \%)$ & $51(16 \%)$ \\
\hline \multicolumn{9}{|l|}{ Non-haematological adverse events } \\
\hline Fatigue* & 147 (45\%) & $39(12 \%)$ & 0 & 0 & $126(38 \%)$ & $18(5 \%)$ & 0 & 0 \\
\hline Neuropathy* & $123(38 \%)$ & $27(8 \%)$ & 0 & 0 & $104(32 \%)$ & $15(5 \%)$ & 0 & 0 \\
\hline Decreased appetite & $121(37 \%)$ & $10(3 \%)$ & 0 & 0 & $92(28 \%)$ & $13(4 \%)$ & 0 & 0 \\
\hline Abdominal pain* & $98(30 \%)$ & $20(6 \%)$ & 0 & 0 & $87(26 \%)$ & $10(3 \%)$ & $\mathrm{I}(<\mathrm{I} \%)$ & 0 \\
\hline Nausea & $109(33 \%)$ & $5(2 \%)$ & $\mathrm{I}(<\mathrm{I} \%)$ & 0 & $100(30 \%)$ & $8(2 \%)$ & 0 & 0 \\
\hline Alopecia & $107(33 \%)$ & 0 & 0 & 0 & $126(38 \%)$ & $\mathrm{I}(<\mathrm{I} \%)$ & 0 & 0 \\
\hline Diarrhoea & 94 (29\%) & $12(4 \%)$ & 0 & 0 & 71 (22\%) & $4(1 \%)$ & $\mathrm{I}(<\mathrm{I} \%)$ & 0 \\
\hline Epistaxis & $100(31 \%)$ & 0 & 0 & 0 & $23(7 \%)$ & 0 & 0 & 0 \\
\hline Vomiting & $78(24 \%)$ & $9(3 \%)$ & $\mathrm{I}(<\mathrm{I} \%)$ & 0 & $56(17 \%)$ & $12(4 \%)$ & 0 & 0 \\
\hline Peripheral oedema & 77 (24\%) & $5(2 \%)$ & 0 & 0 & 43 (I3\%) & $2(<1 \%)$ & 0 & 0 \\
\hline Hypertension & $32(10 \%)$ & $46(14 \%)$ & 0 & 0 & $8(2 \%)$ & $8(2 \%)$ & 0 & 0 \\
\hline Constipation & $70(21 \%)$ & 0 & 0 & 0 & $69(21 \%)$ & $2(<1 \%)$ & 0 & 0 \\
\hline Stomatitis & $62(19 \%)$ & $2(<1 \%)$ & 0 & 0 & $22(7 \%)$ & $2(<1 \%)$ & 0 & 0 \\
\hline Pyrexia & $56(17 \%)$ & $3(<1 \%)$ & 0 & 0 & $36(11 \%)$ & $\mathrm{I}(<\mathrm{I} \%)$ & 0 & 0 \\
\hline Proteinuria & $50(15 \%)$ & $4(1 \%)$ & 0 & 0 & $20(6 \%)$ & 0 & 0 & 0 \\
\hline Malignant neoplasm progression & $5(2 \%)$ & $16(5 \%)$ & $4(1 \%)$ & $27(8 \%)$ & $\mathrm{I}(<\mathrm{I} \%)$ & $24(7 \%)$ & $\mathrm{I}(<\mathrm{I} \%)$ & $34(10 \%)$ \\
\hline Weight decreased & $39(12 \%)$ & $6(2 \%)$ & 0 & 0 & $45(14 \%)$ & $4(I \%)$ & 0 & 0 \\
\hline Dyspnoea & $34(10 \%)$ & $8(2 \%)$ & 0 & 0 & $29(9 \%)$ & $2(<1 \%)$ & 0 & 0 \\
\hline Rash* & $42(13 \%)$ & 0 & 0 & 0 & $31(9 \%)$ & 0 & 0 & 0 \\
\hline Cough & 40 (12\%) & 0 & 0 & 0 & $25(8 \%)$ & 0 & 0 & 0 \\
\hline Back pain & 35 (II\%) & $4(1 \%)$ & 0 & 0 & 35 (II\%) & $5(2 \%)$ & 0 & 0 \\
\hline Hypoalbuminaemia* & $32(10 \%)$ & $4(1 \%)$ & 0 & 0 & $13(4 \%)$ & $2(<1 \%)$ & 0 & $\mathrm{I}(<\mathrm{l} \%)$ \\
\hline Myalgia & $34(10 \%)$ & 0 & 0 & 0 & $32(10 \%)$ & $\mathrm{I}(<\mathrm{I} \%)$ & 0 & 0 \\
\hline Ascites & $21(6 \%)$ & II (3\%) & $\mathrm{I}(<\mathrm{I} \%)$ & 0 & $14(4 \%)$ & $13(4 \%)$ & 0 & 0 \\
\hline Headache & $32(10 \%)$ & 0 & 0 & 0 & $21(6 \%)$ & $\mathrm{I}(<\mathrm{I} \%)$ & 0 & 0 \\
\hline \multicolumn{9}{|l|}{ Haematological adverse events } \\
\hline Neutropenia* & 45 (I4\%) & 7I (22\%) & $62(19 \%)$ & 0 & 40 (I2\%) & $51(16 \%)$ & II (3\%) & 0 \\
\hline Anaemia* & $84(26 \%)$ & $30(9 \%)$ & 0 & 0 & $85(26 \%)$ & $31(9 \%)$ & $3(<1 \%)$ & 0 \\
\hline Leucopenia* & $54(17 \%)$ & $52(16 \%)$ & $5(2 \%)$ & 0 & 47 (14\%) & $19(6 \%)$ & $3(<1 \%)$ & 0 \\
\hline Thrombocytopenia* & $38(12 \%)$ & $5(2 \%)$ & 0 & 0 & $14(4 \%)$ & $6(2 \%)$ & 0 & 0 \\
\hline
\end{tabular}

Notes: Data are number (\%), unless otherwise stated. *Consolidated adverse event category comprising synonymous MEdDRA preferred terms. Reprinted from The Lancet Oncology, volume I5, Wilke H, Muro K, Van Cutsem E, et al, Ramucirumab plus paclitaxel versus placebo plus paclitaxel in patients with previously treated advanced gastric or gastro-oesophageal junction adenocarcinoma (RAINBOW): a double-blind, randomised phase 3 trial. pages I224-1235, Copyright (C) 20I4, with permission from Elsevier. ${ }^{34}$

with fluoropyrimidine or platinum-based chemotherapy. Its approval was subsequently extended to ramucirumab in combination with paclitaxel chemotherapy in November 2014 based on the results of the RAINBOW study. ${ }^{6}$ In the absence of comparative studies, ramucirumab alone or in combination with paclitaxel provides an alternative treatment option to docetaxel or irinotecan chemotherapy in the second-line setting given the similar modest survival benefits and potentially a more favorable side effect profile. However, there have been no comparative trials of ramucirumab versus chemotherapy and its routine use may be limited by access when compared with the availability of inexpensive chemotherapy options such as the taxanes or irinotecan, particularly in health systems with resource constraints or where cost effectiveness is an important consideration for reimbursement. Given that patients included in the REGARD study had a good performance status (ECOG PS 0-1) and organ function, the more meaningful clinical benefit seen with using ramucirumab in combination with paclitaxel chemotherapy in the second-line setting as shown in the RAINBOW study makes this the more preferred approach for patients suitable for combination therapy who are willing to accept the possibility of more treatment-related side effects. However, this has also not been examined in a head-to-head comparative trial.

It remains unclear what percentage of patients who fail first-line therapy will be suitable for and benefit from ramucirumab, given that poor performance status and declining clinical status are common in patients with advanced 
gastric cancer and that all patients included in the trials were very carefully selected populations with good performance status. Quality of life is a particularly important consideration when evaluating suitability of second-line treatment given the poor overall prognosis in these patients with advanced gastric cancer.

Second-line chemotherapy using a taxane or irinotecan may be considered for patients with good ECOG PS who have advanced gastric cancer where ramucirumab is not available. ${ }^{18-20}$ There is currently a lack of data to show that combination chemotherapy would be more effective than monotherapy in this setting. ${ }^{22}$ The optimal second-line approach for patients with HER-2 over-expressing advanced gastric cancers who have disease progression following trastuzumab containing chemotherapy regimens remains unclear although clinical trials with other HER-2 targeting agents are ongoing. Identification of predictive biomarkers in the future may help better identify those who would benefit most from treatment with ramucirumab.

\section{Biomarkers}

It is becoming increasingly evident that the identification of predictive biomarkers in order to best identify those patients who will benefit most from molecularly targeted therapies is very important. However, in patients with gastrointestinal cancers, a validated predictive biomarker to select patients for anti-angiogenic therapy has not been identified to date despite extensive preclinical and clinical research. The AVAGAST trial in advanced gastric cancer showed that baseline plasma VEGF-A and tumor expression of neuropilin were potential predictive markers of efficacy for bevacizumab. ${ }^{63}$ However, a comprehensive evaluation of baseline VEGF-A levels in several Phase III trials of colorectal, lung, and renal cancers showed a trend toward an adverse prognostic effect with higher VEGF-A levels but showed no predictive value for treatment with bevacizumab. ${ }^{64}$ We eagerly await biomarker analysis from the studies of ramucirumab. We consider that mandating tissue and plasma collection within clinical trials to aid biomarker discovery is an essential part of conducting clinical trials.

\section{Future considerations}

The benefits shown with the VEGFR-2 inhibitor, ramucirumab, and the VEGFR-2 tyrosine kinase inhibitor, apatinib, represent important milestones in the development of anti-angiogenic drugs in advanced gastric cancer. Future considerations may include investigating the use of ramucirumab in the first-line setting, in combination with other chemotherapeutic or molecularly targeted agents, its use in maintenance therapy, and sequencing with other active treatments. In particular, the chemotherapy partner appears to be important and warrants further investigation given the positive OS data when combined with paclitaxel that was not seen when ramucirumab was combined with mFOLFOX6. Therefore, the Phase III trial of ramucirumab in combination with cisplatin and capecitabine in first line is eagerly awaited. Dosage and dose intensity are additional issues that may be examined as well as the ramucirumab exposure-survival and ramucirumab exposure-safety relationship. Further post registration studies may provide further safety and efficacy data based on the real world use of ramucirumab that may not have been identified in the Phase III studies given the modest improvement in survival. Given the increasing costs of cancer care, cost-effectiveness analysis should be incorporated into future clinical trials of this agent. Ongoing clinical trials of targeted therapies are outlined in Table 7. Despite promising recent advances in therapeutic treatment options for advanced gastric cancer, which now includes treatments with molecularly targeted agents against VEGFR-2 and HER-2, prognosis remains poor and further research is needed.

\section{Acknowledgment}

The authors would like to thank Herwin Gumulya for technical assistance with graphic design.

Table 7 Ongoing studies of targeted therapies in gastric cancer

\begin{tabular}{llllll}
\hline Trial ID & Clinical trial & Phase & Line & Intervention and schedule & Projected accrual \\
\hline $\begin{array}{l}\text { Angiogenesis inhibitors (Phase II/III) } \\
\text { ACTRNI 26I2000239864 }\end{array}$ & INTEGRATE & II & Second & Regorafenib vs BSC & I50 \\
$\begin{array}{l}\text { Other targeted therapies (Phase III) } \\
\text { NCT0I774786 }\end{array}$ & JACOB & III & First & XP-T with or without pertuzumab & 780 \\
NCT0I450696 & HELOISE & III & First & XP-T (standard) vs XP-T (high dose) & 400 \\
NCT0I64I939 & GATSBY & III & Second & TDM-I vs taxane & $4 I 2$ \\
NCT0I8I3253 & & III & Second & Irinotecan \pm nimotuzumab & 400 \\
NCT0I924533 & & III & Second & Paclitaxel \pm olaparib & 500 \\
\hline
\end{tabular}

Abbreviations: BSC, best supportive care; XP, cisplatin and capecitabine; T, trastuzumab; TDM-I, trastuzumab emtansine. 


\section{Disclosure}

MMKC has received travel support from Merck Sharp and Dohme. KMS was a member of the Trial Management Committee for the INTEGRATE study. JRZ has received compensation for Advisory Boards conducted by Lilly, Amgen, Hoffman-La Roche Ltd, and Bayer; research support from Amgen, Hoffman-La Roche Ltd, and Bayer; and travel support from Roche and Bayer. JRZ was also a member of the Trial Management Committee for the REGARD study. The authors report no conflicts of interest in this work.

\section{References}

1. Ferlay J, Soerjomataram I, Ervik M, et al. GLOBOCAN 2012 v1.0 Cancer Incidence and Mortality Worldwide: IARC CancerBase No. 11 [database on the Internet]. Lyon, France: International Agency for Research on Cancer; 2013. Available from: http://globocan.iarc.fr. Accessed September 1, 2014.

2. Cunningham D, Allum WH, Stenning SP, et al. Perioperative chemotherapy versus surgery alone for resectable gastroesophageal cancer. N Engl J Med. 2006;355:11-20.

3. Bang YJ, Kim YW, Yang HK, et al. Adjuvant capecitabine and oxaliplatin for gastric cancer after D2 gastrectomy (CLASSIC): a phase 3 open-label, randomised controlled trial. Lancet. 2012;379:315-321.

4. Sasako M, Sakuramoto S, Katai H, et al. Five-year outcomes of a randomized phase III trial comparing adjuvant chemotherapy with S-1 versus surgery alone in stage II or III gastric cancer. J Clin Oncol. 2011;29:4387-4393.

5. Paoletti X, Oba K, Burzykowski T, et al. Benefit of adjuvant chemotherapy for resectable gastric cancer: a meta-analysis. JAMA. 2010;303: 1729-1737.

6. Macdonald JS, Smalley SR, Benedetti J, et al. Chemoradiotherapy after surgery compared with surgery alone for adenocarcinoma of the stomach or gastroesophageal junction. $N$ Engl J Med. 2001;345:725-730.

7. Wagner $\mathrm{AD}$, Unverzagt $\mathrm{S}$, Grothe $\mathrm{W}$, et al. Chemotherapy for advanced gastric cancer. Cochrane Database Syst Rev. 2010;CD004064.

8. Cunningham D, Starling N, Rao S, et al. Capecitabine and oxaliplatin for advanced esophagogastric cancer. $N$ Engl J Med. 2008;358:36-46.

9. Al-Batran SE, Hartmann JT, Probst S, et al. Phase III trial in metastatic gastroesophageal adenocarcinoma with fluorouracil, leucovorin plus either oxaliplatin or cisplatin: a study of the Arbeitsgemeinschaft Internistische Onkologie. J Clin Oncol. 2008;26:1435-1442.

10. Kang Y-K, Kang W-K, Shin D-B, et al. Capecitabine/cisplatin versus 5 -fluorouracil/cisplatin as first-line therapy in patients with advanced gastric cancer: a randomised phase III noninferiority trial. Ann Oncol. 2009;20:666-673.

11. Koizumi W, Narahara H, Hara T, et al. S-1 plus cisplatin versus S-1 alone for first-line treatment of advanced gastric cancer (SPIRITS trial): a phase III trial. Lancet Oncol. 2008;9:215-221.

12. Van Cutsem E, Moiseyenko VM, Tjulandin S, et al. Phase III study of docetaxel and cisplatin plus fluorouracil compared with cisplatin and fluorouracil as first-line therapy for advanced gastric cancer: a report of the V325 Study Group. J Clin Oncol. 2006;24:4991-4997.

13. Wagner AD, Grothe W, Haerting J, et al. Chemotherapy in advanced gastric cancer: a systematic review and meta-analysis based on aggregate data. J Clin Oncol. 2006;24:2903-2909.

14. Boku N, Yamamoto S, Fukuda H, et al. Fluorouracil versus combination of irinotecan plus cisplatin versus S-1 in metastatic gastric cancer: a randomised phase 3 study. Lancet Oncol. 2009;10:1063-1069.

15. Ajani JA, Rodriguez W, Bodoky G, et al. Multicenter phase III comparison of cisplatin/S-1 with cisplatin/infusional fluorouracil in advanced gastric or gastroesophageal adenocarcinoma study: the FLAGS trial. J Clin Oncol. 2010;28:1547-1553.
16. The_GASTRIC_Group: Role of chemotherapy for advanced/recurrent gastric cancer: An individual-patient-data meta-analysis. Eur J Cancer. 2013;49:1565-1577.

17. Bang YJ, Van Cutsem E, Feyereislova A, et al. Trastuzumab in combination with chemotherapy versus chemotherapy alone for treatment of HER2-positive advanced gastric or gastro-oesophageal junction cancer (ToGA): a phase 3, open-label, randomised controlled trial. Lancet. 2010;376:687-697.

18. Kang JH, Lee SI, Lim do H, et al. Salvage chemotherapy for pretreated gastric cancer: a randomized phase III trial comparing chemotherapy plus best supportive care with best supportive care alone. J Clin Oncol. 2012;30:1513-1518

19. Ford HER, Marshall A, Bridgewater JA, et al. Docetaxel versus active symptom control for refractory oesophagogastric adenocarcinoma (COUGAR-02): an open-label, phase 3 randomised controlled trial. Lancet Oncol. 2014;15:78-86.

20. Thuss-Patience PC, Kretzschmar A, Bichev D, et al. Survival advantage for irinotecan versus best supportive care as second-line chemotherapy in gastric cancer-a randomised phase III study of the Arbeitsgemeinschaft Internistische Onkologie (AIO). Eur J Cancer. 2011;47: 2306-2314.

21. Kim HS, Kim HJ, Kim SY, et al. Second-line chemotherapy versus supportive cancer treatment in advanced gastric cancer: a meta-analysis. Ann Oncol. 2013;24:2850-2854.

22. Hironaka S, Ueda S, Yasui H, et al. Randomized, open-label, phase III study comparing irinotecan with paclitaxel in patients with advanced gastric cancer without severe peritoneal metastasis after failure of prior combination chemotherapy using fluoropyrimidine plus platinum: WJOG 4007 Trial. J Clin Oncol. 2013;31:4438-4444.

23. Higuchi K, Tanabe S, Shimada K, et al. Biweekly irinotecan plus cisplatin versus irinotecan alone as second-line treatment for advanced gastric cancer: a randomised phase III trial (TCOG GI-0801/BIRIP trial). Eur J Cancer. 2014;50:1437-1445.

24. Lordick F, Kang YK, Chung HC, et al. Capecitabine and cisplatin with or without cetuximab for patients with previously untreated advanced gastric cancer (EXPAND): a randomised, open-label phase 3 trial. Lancet Oncol. 2013;14:490-499.

25. Waddell T, Chau I, Cunningham D, et al. Epirubicin, oxaliplatin, and capecitabine with or without panitumumab for patients with previously untreated advanced oesophagogastric cancer (REAL3): a randomised, open-label phase 3 trial. Lancet Oncol. 2013;14:481-489.

26. Ohtsu A, Ajani JA, Bai Y-X, et al. Everolimus for previously treated advanced gastric cancer: results of the randomized, double-blind, phase III GRANITE-1 Study. J Clin Oncol. 2013;31:3935-3943.

27. Satoh T, Xu R-H, Chung HC, et al. Lapatinib plus paclitaxel versus paclitaxel alone in the second-line treatment of HER2-amplified advanced gastric cancer in Asian populations: TyTAN - A randomized, phase III study. J Clin Oncol. 2014;32:2039-2049.

28. Hoff P, Tabernero J, Shen L, et al. P-0111 pertuzumab, trastuzumab and chemotherapy in HER2-positive metastatic gastric or gastrooesophageal junction cancer: an international phase III study (JACOB). Ann Oncol. 2013;24:iv67.

29. Shah M, Cho J, Huat I, et al. Randomized phase II study of FOLFOX \pm MET inhibitor, onartuzumab $(\mathrm{O})$, in advanced gastroesophageal adenocarcinoma (GEC). J Clin Oncol. 2015;33(Suppl 3): abstr 2.

30. Bang Y, Im S, Lee K, et al. Olaparib plus paclitaxel in patients with recurrent or metastatic gastric cancer: a randomized, double-blind phase II study. J Clin Oncol. 2013;31:abstr 4013.

31. Ohtsu A, Shah MA, Van Cutsem E, et al. Bevacizumab in combination with chemotherapy as first-line therapy in advanced gastric cancer: a randomized, double-blind, placebo-controlled phase III study. J Clin Oncol. 2011;29:3968-3976.

32. Shen L, Li J, Xu J, et al. Bevacizumab plus capecitabine and cisplatin in Chinese patients with inoperable locally advanced or metastatic gastric or gastroesophageal junction cancer: randomized, doubleblind, phase III study (AVATAR study). Gastric Cancer. 2015;18: $168-176$. 
33. Fuchs CS, Tomasek J, Yong CJ, et al. Ramucirumab monotherapy for previously treated advanced gastric or gastro-oesophageal junction adenocarcinoma (REGARD): an international, randomised, multicentre, placebo-controlled, phase 3 trial. Lancet. 2014;383:31-39.

34. Wilke H, Muro K, Van Cutsem E, et al. Ramucirumab plus paclitaxel versus placebo plus paclitaxel in patients with previously treated advanced gastric or gastro-oesophageal junction adenocarcinoma (RAINBOW): a double-blind, randomised phase 3 trial. Lancet Oncol. 2014; $15: 1224-1235$.

35. Qin S. Phase III study of apatinib in advanced gastric cancer: a randomized, double-blind, placebo-controlled trial. J Clin Oncol. 2014;32(Suppl 1): abstr 4003 .

36. Hanahan D, Weinberg RA. Hallmarks of cancer: the next generation. Cell. 2011;144:646-674.

37. Kerbel RS. Tumor angiogenesis. $N$ Engl J Med. 2008;358: 2039-2049.

38. Ferrara N, Kerbel RS. Angiogenesis as a therapeutic target. Nature. 2005;438:967-974.

39. Holmes K, Roberts OL, Thomas AM, et al. Vascular endothelial growth factor receptor-2: structure, function, intracellular signalling and therapeutic inhibition. Cell Signal. 2007;19:2003-2012.

40. Hicklin DJ, Ellis LM. Role of the vascular endothelial growth factor pathway in tumor growth and angiogenesis. J Clin Oncol. 2005;23: 1011-1027.

41. Aprile G, Bonotto M, Ongaro E, et al. Critical appraisal of ramucirumab (IMC-1121B) for cancer treatment: from benchside to clinical use. Drugs. 2013;73:2003-2015.

42. Maeda K, Chung Y-S, Ogawa Y, et al. Prognostic value of vascular endothelial growth factor expression in gastric carcinoma. Cancer. 1996;77:858-863.

43. Lieto E, Ferraraccio F, Orditura M, et al. Expression of vascular endothelial growth factor (VEGF) and epidermal growth factor receptor (EGFR) is an independent prognostic indicator of worse outcome in gastric cancer patients. Ann Surg Oncol. 2008;15:69-79.

44. Yi JH, Lee J, Lee J, et al. Randomised phase II trial of docetaxel and sunitinib in patients with metastatic gastric cancer who were previously treated with fluoropyrimidine and platinum. $\mathrm{Br} J$ Cancer. 2012;106:1469-1474.

45. Sun W, Powell M, O'Dwyer PJ, et al. Phase II study of sorafenib in combination with docetaxel and cisplatin in the treatment of metastatic or advanced gastric and gastroesophageal junction adenocarcinoma: ECOG 5203. J Clin Oncol. 2010;28:2947-2951.

46. Pavlakis N, Sjoquist K, Tsobanis E, et al. INTEGRATE: A randomized phase II double-blind placebo-controlled study of regorafenib in refractory advanced oesophagogastric cancer (AOGC) - A study by the Australasian Gastrointestinal Trials Group (AGITG), first results. J Clin Oncol. 2015;33(Suppl 3): abstr 9.

47. Li J, Qin S, Xu J, et al. Apatinib for chemotherapy-refractory advanced metastatic gastric cancer: results from a randomized, placebo-controlled, parallel-arm, phase II trial. J Clin Oncol. 2013;31:3219-3225.

48. Garon EB, Ciuleanu TE, Arrieta O, et al. Ramucirumab plus docetaxel versus placebo plus docetaxel for second-line treatment of stage IV non-small-cell lung cancer after disease progression on platinum-based therapy (REVEL): a multicentre, double-blind, randomised phase 3 trial. Lancet. 2014;384:665-673.

49. Mackey JR, Ramos-Vazquez M, Lipatov O, et al. Primary results of ROSE/TRIO-12, a randomized placebo-controlled phase III trial evaluating the addition of ramucirumab to first-line docetaxel chemotherapy in metastatic breast cancer. J Clin Oncol. 2015;33:141-148.

50. Tabernero J, Yoshino T, Cohn AL, et al. Ramucirumab versus placebo in combination with second-line FOLFIRI in patients with metastatic colorectal carcinoma that progressed during or after first-line therapy with bevacizumab, oxaliplatin, and a fluoropyrimidine (RAISE): a randomised, double-blind, multicentre, phase 3 study. Lancet Oncol. Epub April 13, 2015.
51. Zhu AX, Ryoo BY, Yen CJ, et al. Ramucirumab (RAM) as second-line treatment in patients (pts) with advanced hepatocellular carcinoma (hcc) following first-line therapy with sorafenib: results from the randomized phase III REACH study. Ann Oncol. 2014;25:LBA16.

52. Spratlin JL, Cohen RB, Eadens M, et al. Phase I pharmacologic and biologic study of ramucirumab (IMC-1121B), a fully human immunoglobulin G1 monoclonal antibody targeting the vascular endothelial growth factor receptor-2. J Clin Oncol. 2010;28:780-787.

53. Witte L, Hicklin DJ, Zhu Z, et al. Monoclonal antibodies targeting the VEGF receptor-2 (Flk1/KDR) as an anti-angiogenic therapeutic strategy. Cancer Metastasis Rev. 1998;17:155-161.

54. Prewett M, Huber J, Li Y, et al. Antivascular endothelial growth factor receptor (fetal liver kinase 1) monoclonal antibody inhibits tumor angiogenesis and growth of several mouse and human tumors. Cancer Res. 1999;59:5209-5218.

55. Lu D, Shen J, Vil MD, et al. Tailoring in vitro selection for a picomolar affinity human antibody directed against vascular endothelial growth factor receptor 2 for enhanced neutralizing activity. $J$ Biol Chem. 2003;278:43496-43507.

56. Miao HQ, Hu K, Jimenez X, et al. Potent neutralization of VEGF biological activities with a fully human antibody Fab fragment directed against VEGF receptor 2. Biochem Biophys Res Commun. 2006;345: 438-445.

57. Wadhwa R, Taketa T, Sudo K, et al. Ramucirumab: a novel antiangiogenic agent. Future Oncol. 2013;9:789-795.

58. Chiorean E, Sweeney C, Hurwitz H, et al. Phase I dose-escalation study of the anti-VEGFR-2 recombinant human IgG1 MAb IMC-1121B administered every other week (q2w) or every 3 weeks (q3w) in patients (pts) with advanced cancers. Mol Cancer Therapeut. 2007;6:B15.

59. Stein MN, Chow LQM, Smith DC, et al. Phase II study evaluating the effect of concomitant ramucirumab (IMC-1121B; RAM) on the pharmacokinetics (PK) of docetaxel (DOC) in patients (pts) with advanced malignant solid tumors. J Clin Oncol. 2014;32(Suppl 15S): abstr e13539.

60. Chow LQM, Smith DC, Tan AR, et al. Phase II study evaluating the effect of concomitant ramucirumab (IMC-1121B; RAM) on the pharmacokinetics (PK) of paclitaxel (PTX) and the PK of RAM as monotherapy in patients (pts) with advanced malignant solid tumors. J Clin Oncol. 2014;32(Suppl 15S): abstr e13554.

61. Yoon HH, Bendell JC, Braiteh FS, et al. Ramucirumab (RAM) plus FOLFOX as front-line therapy $(\mathrm{Rx})$ for advanced gastric or esophageal adenocarcinoma (GE-AC): randomized, double-blind, multicenter phase 2 trial. J Clin. Oncol. 2014;32(Suppl 15S): abstr 4004:256S

62. Ramucirumab in combination with paclitaxel. US Food and Drug Administration; US Department of Health and Human Service. Available from: http://www.fda.gov/Drugs/InformationOnDrugs/ApprovedDrugs/ucm421930.htm. Accessed January 26, 2015.

63. Van Cutsem E, de Haas S, Kang YK, et al. Bevacizumab in combination with chemotherapy as first-line therapy in advanced gastric cancer: a biomarker evaluation from the AVAGAST randomized phase III trial. J Clin Oncol. 2012;30:2119-2127.

64. Hegde PS, Jubb AM, Chen D, et al. Predictive impact of circulating vascular endothelial growth factor in four phase III trials evaluating bevacizumab. Clin Cancer Res. 2013;19:929-937. 


\section{Publish your work in this journal}

Biologics: Targets \& Therapy is an international, peer-reviewed journal focusing on the patho-physiological rationale for and clinical application of Biologic agents in the management of autoimmune diseases, cancers or other pathologies where a molecular target can be identified. This journal is indexed on PubMed Central, CAS, EMBase, Scopus
Dovepress

and the Elsevier Bibliographic databases. The manuscript management system is completely online and includes a very quick and fair peerreview system, which is all easy to use. Visit http://www.dovepress. com/testimonials.php to read real quotes from published authors. 